\title{
ARTIFICIAL NEURAL NETWORK FOR PREDICTION AND CONTROL OF BLASTING VIBRATIONS IN ASSIUT LIMESTONE QUARRY-EGYPT
}

\author{
Mostafa Tantawy Mohamed
}

Mining \& Metallurgical Dept., Faculty of Eng., Assiut University

\begin{abstract}
:
The prediction of ground vibration remains a challenging problem for mines, quarries and construction sites. Many numbers of predictor equations have been proposed by various researchers all over the world to predict ground vibration prior to blasting. Till now, it is difficult to recommend any one general predictor for all blasting conditions because ground vibration is influenced by a number of parameters. These parameters are either controllable or non-controllable like blast geometry, explosive types, rock strength properties, geological conditions, and etc. In the this paper, an attempt has been made to predict the ground vibration using an Artificial Neural Network models (ANN) by single, two, and large number inputs of blasting parameters, which have an effect on the ground vibration. Comparison between neural net work models to each other and also to conventional statistical regression models has been done. It has been found that, the prediction is better by increasing the variable inputs of neural network and it is much more accurate than empirical statistical regression model.
\end{abstract}

